\title{
Dodging Dysfunctional Dynamics In Power Exchange
}

David P. Boyd, Northeastern University, USA

\begin{abstract}
In today's organizations, the impetus for employee empowerment remains strong. By developing an internal talent base, companies increase the likelihood of comprehensive contributions and also engender loyalty within the ranks. A proclivity for power dispersion is evident among many pundits, with some even decreeing it an ethical mandate. Yet, if rashly executed, empowerment can result in dire outcomes for the individual and dysfunctional consequences for the firm. Through reference to the medium of film, this paper portrays four situations where empowerment efforts have gone awry, accentuating employee estrangement and eroding corporate ethics. Because the behavioral dynamics of film are frozen in time and thus susceptible to recursive scrutiny, students can glean institutional insights that will facilitate career advancement. Just as important, they will confront value conflicts that impel them to clarify their own ethical stance.
\end{abstract}

Keywords: Films, Empowerment, Ethics

\section{INTRODUCTION: CINEMATIC VIGNETTES AND OBSERVATIONAL LEARNING}

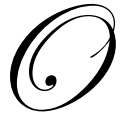

ver the past four decades, film has been part of the educational panoply that informs business school curriculum. For several reasons, cinema has proven an adroit vehicle to depict the connection between action and consequence. First, the plot typically unfolds in a chronological sequence, thus enabling the viewer to ascertain antecedents as well as outcomes (Giacalone and Jurkiewicz, 2001). It then becomes easier to place discrete events in an organizational context and gain perspective on the total system that frames those acts (Lewicki and Bunker, 1996). Second, the film affords a permanent record of behavioral dynamics where interaction is frozen in time; the viewer may thus have repeated recourse to the film and witness any encounter exactly as it occurred. In this manner, the clarity of recursion can supersede the confusion of recall (Boyd, 2009). As in literature, the viewer enjoys a vantage point of "relative omniscience" ( Michaelson et al., 2006). Finally, films provide exposure to affective as well as cognitive dimensions (Proctor and Adler, 1991). Observational technique can highlight value conflicts that arise in the workplace. In the course of analyzing the values of these third parties, student viewers become more cognizant of their own moral ground. Since students learn by looking, observation becomes the pedagogical rationale for the use of film in skills development (Serey, 1992). Through the classroom "workshop," participants can ascertain how their personal values align with the professional and organizational values profiled through the medium of film (Van Es, 2003). Lauder (2002) opines that "beautiful stories have the power to help us be moral." Perhaps, too, ugly stories have the power to help us avoid immorality.

\section{Ethics of Empowerment}

The benefits of empowerment are widely touted. The concept is culturally consonant with the popular notion of dispersed leadership. Leadership is a distributed phenomenon predicated on pluralism. This encompassing purview is more than a normative ideal; it is a survival tactic for the organization since no helmsman has a monopoly on wisdom. Leaders must wander down from the mountain top and converse with those in the village. "Listen to those on the periphery", admonished a former CEO of Intel. Those closest to the action can divine impending danger. By actively engaging them, the nominal organizational leaders can be alert to both threat and opportunity. Should there be any harbinger of adversity, the firm can proactively respond. 
Dispersion of power and leadership also strengthens the organizational ranks, thereby lessening the likelihood that the firm will be held hostage to a select - and potentially peripatetic - cadre at the helm. Empowered employees often perceive a heightened sense of self-efficacy that propels action and accomplishment. If top management is sensitive to power dynamics, they realize that such initiatives make everyone - themselves included - look better. They also know that by sharing power, they accrue more. Employees appreciate the gift of trust and often augment their commitment because they feel obligatory reciprocity to prove they deserve the responsibility accorded them. Recent studies across a global context show that empowerment can boost firm performance (Anita et al., 2007).

Given the salutary effects of employee empowerment, many scholars view it as an "ethical imperative." Kanungo (1992), for example, proclaims that employers have a moral obligation to develop the members of their work community. As more and more individuals acquire skills, their new-found capabilities will enhance the organization and fortify the overall social fabric. In this vein, various scholars have suggested the empowerment construct be viewed as a key dealienation strategy (Block, 1987; Kanter, 1980). However, the purpose of this paper is to show that under some circumstances, empowerment can itself be a cause of alienation. If not judiciously deployed, empowerment can accelerate estrangement rather than alleviate it. Once empowered, individuals must still appreciate the constant interplay of dependence and independence. By referencing moral dilemmas presented in film, this paper will present four situational contexts where that sense of balance is likely to be lost and the redemptive effects of empowerment never realized.

\section{THOSE WHO SANCTION POWER}

\section{Dead Poets Society - Seeking Redemption through Rejection}

In a 1950s boarding school called Welton, an English teacher engages in extraordinary behaviors associated with charismatic leadership. Mr. Keating exhorts his students to probe their inner self and recognize the legitimacy of self-defined goals. As a way of proclaiming personal identity, they should "seize the day" and activate their inclinations unfettered by shackles of the school. Keating's iconoclastic message seeks to empower his charges by encouraging them to embrace individual aspirations even as they eschew institutional expectations. In Keating's mind "carpe diem" represents the triumph of empowerment over enslavement. The sanctity of expressionism should supersede the structure of establishment Boyd, 2008). As Navahandi (2009) observes, some present-day researchers recommend that organizations and employees reject all vestiges of authority. Keating's persona would resonate with these revolutionaries.

Yet Keating myopically assumes his young charges can seize the day before he himself seeds the way. The school is steeped in traditional values and behaviors. Its institutional authority makes no provision for individual autonomy. Keating ignores the school's administrators, provoking their wrath rather than inviting their collaboration. Even were they able to comprehend Keating's new-fangled approach, they would never condone it. To them self-actualization in the classroom is tantamount to self-indulgence. Keating's high-spirited mischief threatens to corrupt the culture. To sustain relevance and ensure viability, learning organizations must continuously add to their knowledge inventory. However, they must first grasp the necessity of doing so. Keating makes no attempt to convert his peers. By failing to prepare colleagues for his change efforts, he forecloses any possibility of cultural adaptation. Keating's empowerment efforts lack a contextual orientation. His grassroots initiative does not align with the school's core values and so it will be maligned by the cultural custodians.

Keating shows even less responsibility for those under his tutelage. His students were acclimated to tight boundaries. When they breeched these psychological barriers, they discovered that confusion ensues from freedom prematurely conferred (Boyd, 2008). Even though they reject the surface acting (Grandey, 2000, 2003) required of them, Welton students find their emotional exhaustion and cognitive dissonance deepen. They are neither psychologically nor politically empowered for the unchartered waters they enter. Lacking knowledge and skills, these adolescents are not imbued with a sense of competence and mastery; deprived of self-efficacy, they are unlikely to be organizational contributors (Spreitzer \& Doneson, 2008). Their learned hopefulness fades into learned helplessness (Zimmerman, 1990). One pupil's guilt about abandoning the world of codified behavior even leads to suicide. His untimely end ensures Keating's dismissal. Keating leaves the school as befuddled as his 
stumbling students. He has been wont to pay homage to Walt Whitman's "Captain." Ironically, "the ship is anchor'd safe and sound" once more but the captain of the classroom has gone down. The young crew may mourn his departure but a relentless reversion to steady state will dim the memory of their onetime liberator.

\section{Takeaways for Managers about to Empower Others}

1. Allow time for individual adjustment and adaptation, especially with young charges or those who have never experienced unregulated work behavior. If employers reduce restrictive institutional mores too quickly, employees may be confounded by the myriad of evolving elements that comprise today's nonbureaucratic structures. Ongoing leader support is necessary for improved employee performance (Logan and Ganster, 2007).

2. Since cultural legacy can be time-honored, change agents might foster assimilation through a strategy of small wins. Rather than summarily dispensing with the old, move incrementally toward the new. Keating tore out all the pages of the classroom tome when he could have selectively focused on certain chapters or quietly segued into a new text.

\section{Thank You for Smoking - Seeking Redemption through Rationalism}

The tobacco industry is under assault and Nick Naylor is a lobbyist who intends to rescue it. In his campaign to spread smoking, he proves himself an effective leader but one who relies on unethical change methods. Naylor is a charismatic figure with strong conviction and imposing self-confidence. He has a keen social awareness and uses it to advantage. In an instant he can forge close connections. The film repeatedly shows how he can enter a room, scope the audience, and determine the best way to address them. This power of assessment lets him prevail over those less conversant. In the "Cancer Boy Scene," where he is initially under fire from a live TV audience, he deftly changes sentiment by invoking his power of persuasion. Nick declaims that the tobacco industry would never encourage smoking among young people. He rhetorically queries: "Why would we try to kill our prime customers?". Again and again Naylor is able to connect things that are not necessarily congruent.

Lurking behind his every utterance is Machiavellian intent. Nick never says his side of the debate is correct. Rather he argues that the other side is wrong. He thus affords adversaries an opportunity to agree with him and change their minds. While before a Senate Committee, at no point does he deny that cigarettes merit the skull and bones insignia. He simply points out that if the Committee requires such a mandate, it is tantamount to declaring the American public stupid. Nick does not ostensibly use the bully pulpit to encourage smoking. Instead he exhorts his audience to think for themselves and cast aside the strictures of sanctimonious critics. Nick unfurls the banner of personal freedom and appears bent on a mission of social betterment. His quest is to make people think twice about what they are told. Move the locus of control away from media rants and center decisions in one's own rational mind. By the end of the film, Nick may have been educated by his own son. He seems to acknowledge that his persuasive motivation may be nothing more than perverse manipulation. Yet even in apparent defeat, he retains the sympathy of film viewers. Despite his abhorrent actions, we feel the pull of his persona.

\section{Takeaways for Managers about to Empower Others}

1. A few critics find the notion of empowerment to be patronizing and condescending (Clarke \& Crossland, 2002). To such scholars the bestowal of benevolence ironically palliates hierarchical differentiation by giving it a cast of noblesse oblige. More to the point, though, these seemingly benign overtures can belie the conspiratorial intent of those who seek to manipulate us. Behind their avowedly altruistic dispersal of power, they are attempting to accrue more. Their time-honored argument that nothing can be proven is mere Socratic spin; if they ask enough questions, they know they can wiggle out of being wrong.

2. There are those who exploit the concept of personal responsibility and consumer choice. If the burden for addressing harm rests solely with the consumer, companies who manufacture would be deemed exempt from liability - and those who frame policy would be impeded in their legislative quest. Personal responsibility would then trump public reform. The target of the movie is lobbyists whose unabashed goal is to make perilous products palatable in the eyes of those who would buy them. Such advocates resort to rationalization in the name of rationalism. 


\section{THOSE WHO SEIZE POWER}

\section{Office Space - Seeking Redemption through Revolt}

Leaders must possess qualities that inspire people to follow them and emulate their example. In the film "Office Space," Bill Lumburgh makes no attempt to understand his employees' frame of reference and appeal to them on that level. His callous disregard precludes any search for common ground. He fails to encourage the reciprocity that feedback allows. Seemingly oblivious to the higher-level needs of his young software engineers, he deprives them of any opportunity for independence, creativity, or responsibility. He is superficial in his approach to both people and things; he is concerned with a report's cover sheet but not its content. The office setting is reminiscent of the Intel video produced by comedian Conan O'Brien. The cubicles bar conversation but accentuate noise. As O'Brien observes: "It makes people feel that they are basically the same ... that there is no hope" (Clark, 2007). Rather than being organizational citizens, employees are Dilbert characters. In the movie an employee named Peter starkly sums up the situation: "Every day of work is worse than the day before."

Over time the apathy of these twenty-something professionals morphs into aversion. Peter is charismatic and knows how to deploy personal power with peers. He convinces them to engage in illegal activity and concocts a computer scheme to defalcate the firm. Ironically, Peter's bosses cannot get him to fulfill the legitimate mandate of working efficiently, but Peter can persuade his claustrophobic colleagues to act illegally. These young actors believe they have a right to attack and hack; their new sub-rosa remuneration will begin to redress the gap between them and their bosses. Later Peter manifests his malaise with the firm's consultants who are impressed with his penchant for crisp and candid assessment. Although now on the road to legitimate positional power, his scheme inevitably unravels. It culminates in fiery destruction of the firm and Peter's cohort is once again mired in nihilistic stupor.

The movie makes worker rage seem right. In the end there are no sanctions for pilfering. The satiric tone skirts discussion of employee honesty. The denouement is also disquieting because no new order beckons these moral renegades. They have smashed machines and seen their building burn. They have vanquished the enemy, but estrangement still enshrouds them. Peter remains in vacuous space. Although he has obliterated objects of disdain, he has no attachments to assume their place. Display rules (Grandy, 2000) are gone but so is the world they circumscribed.

\section{Takeaways for Employees about to Empower Themselves}

1. The determination to break away in and of itself provides no bridge to a new world. Destruction of the old should never be the sole focus. First find an idealized environment in which one's job role can be recast. The misery of the present situation can be a clue and a catalyst to settings where one will thrive.

2. Crime can become an expressway for innate creativity, but this avenue will be a dead end. Illegal comeuppance has consequences for the perpetrator. The film, though, is not meant to belabor the obvious crime and punishment theme. Rather it underscores that creative chicanery, when initially conceived, can appear captivating. Evil is enticing because it can assume so many different guises while good is often encased within monolithic parameters. Yet Peter's caper provides no panacea for his angst. He ends as he emerged: a capable person with no point to his existence.

\section{Star Chamber - Seeking Redemption through Remediation}

The film derives its title from an infamous seventeenth century English court that dispensed compensatory justice whenever the larger legal system failed to impose severe sentences upon enemies of the King. This extremist film takes aim not only at egregious crimes but also at the loopholes that eviscerate enforcement efforts for conviction. As a consequence of such miscarriage, a secret organization of judges decides to "fix" a system that is unable to fix itself. They flout the dictum of liberty by law and resort to murder by proxy when horrific deeds go unpunished in the formal courts. The Star Chamber has an inclination to legitimate its role and laud its brand of vigilante justice as a protective service to the public. The Chamber views these incorrigible criminals as subordinate citizens; left unchecked, they will beget more violence. 
The Chamber's latest inductee is young Judge Hardin played by Michael Douglas. His daily fare of murderers disillusions him but the fragility of the law disillusions him even more. Having presided when technicalities prevented punishment of heinous deeds, Hardin initially welcomes the omnipotent role that he and his renegade colleagues have covertly seized. His anger toward scurrilous defendants and his empathy toward victims can now be summarily resolved, relieving him of moral dissonance. As the film progresses, however, Hardin begins to wonder whether he can truly endorse the notion of a righteous kill. Even if laws are in need of change, can he nonetheless break them? Can he recast his conscience to allow conspiratorial complicity in deploying assassins? Can the occasional Star Chamber mistake be rationalized as collateral damage? The Chamber's method of social remediation is not only savage but it may also be simplistic.

As Hardin expresses his growing and gnawing doubt, he himself becomes the target of a Chamber assassin and the film's genre becomes more akin to dramatic thriller than philosophic treatise. Nonetheless, the moral takeaway is clear: justice should be systemically determined and is not the province of a clandestine self-appointed group. If such a group flouts the law, its justice is not just. Vengeance has appeal as a "rectifier" when the system fails. At first glance it might seem a deceptively easy card to play. Yet for those involved in such duplicitous schemes, the rationale soon disintegrates. As members become enmeshed in their own nefarious conduct, protection of self supersedes protection of society. Those who try to exit the group are likely to become as hapless as any murder victim from their own courtroom.

\section{Takeaways for Employees about to Empower Themselves}

1. Retribution can confer psychic reward, but the premise is selfish pleasure rather than social principle. In Kant's terms such moral aggrandizement confuses "motives of inclination" with "motives of duty." The categorical imperative demands that we universalize the principle on which we act. If we allow exceptions, compelling though they seem, we erode the foundation of moral observance (Sandel, 2009).

2. Whether the stage be the courtroom or the boardroom, those who wield absolute power will become oblivious to its true effects and eventually their power will be neutralized (Maslin, 1983). When an organizational echelon usurps power, it will ultimately implode it if makes no provision for flexibility. Single-minded fervor can curtail compromise and constrain creativity. A "sanctified" mission can prevent a nuanced approach to problem resolution. Zealots are often dismissive of different but more salutary steps toward goal attainment. A myopic mindset is a recipe for malfeasance.

\section{CONCLUSION}

Empowerment is an appealing concept because it at once allows worker growth and institutional democratization. For those not equipped to receive it, however, empowerment can present value enigmas that psychologically pre-empt the exercise of newfound power. In "Dead Poets Society," the result for one unshackled student is suicide. Moreover, if conferred without forethought, empowerment can ensnare the very employees that it professes to liberate. In "Thank You for Smoking," those duped by the tobacco lobbyist nod in affable agreement, including the young lad who is himself afflicted by cancer.

The paper also explores two films where protagonists empower themselves. In both cases, they successfully augment their power base. Yet, in neither situation does power accrual bring a sense of earned accomplishment or inner peace. The rising star in "Office Space" cannot be rescued from his moral malaise. Since his values do not align with the corporate culture, he can never be comfortable within it, no matter what his title might be. In the "Star Chamber," Judge Hardin overcomes his moral myopia and realizes that despite the occasional imperfections of the legal system, he may not operate beyond it. As a judge, he, of all people, is bounded by the law. He is formally appointed to a structured role in society and cannot surreptitiously anoint himself with auxiliary power. 
Table 1: Dysfunctional Dynamics in Power Exchange

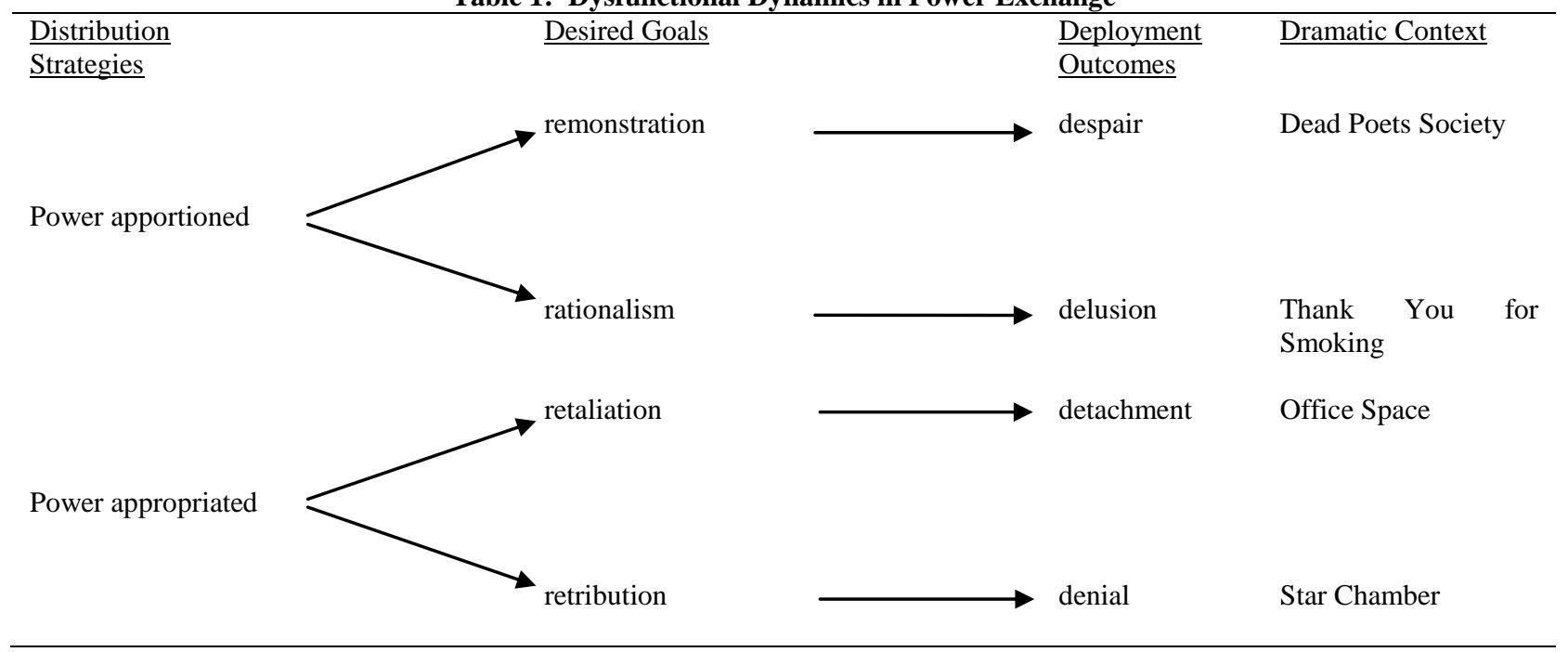

Visual media can convey vivid lessons because they are a pliable delivery mechanism and a didactic presentation methodology. A scene can be frozen in time to allow reflective review; it can be recursively scrutinized so lessons are never obscured by the signal noise that accompanies real world transaction. This kind of vicarious experience can ready students for the workplace. Films, such as the four depicted in Table 1, are a dramatic extrapolation of social reality. Engagement in the viewing process thus allows extension beyond it. By avoiding traps that have entangled screen characters, students can enhance their own possibilities for material success and moral satisfaction.

\section{AUTHOR INFORMATION}

David P. Boyd is Professor of Management and Organizational Development in Northeastern University's College of Business Administration where he served as dean for seven years. Professor Boyd has published over fifty articles in the area of organizational psychology and entrepreneurial leadership. His work has appeared in such journals as the Harvard Business Review, the Sloan Management Review, and the Journal of Management. He holds a BA from Harvard University and a D.Phil. from Oxford University, England.

\section{REFERENCES}

1. Anita, M., Liu, M., Chiu, W., \& Fellows, R. (2007). "Enhancing Commitment through Work Empowerment," Engineering, Construction and Architectural Management, 14, 6: 568-574.

2. Block, P. (1987). The Empowered Manager. San Francisco, CA: Jossey-Bass.

3. Boyd, D. P. (2009). “Cinematic Perspectives on Organizational Mentoring," Contemporary Issues in Education Research, 2, 2: 9-16.

4. Boyd, D. P. (2008). "Dramatic Depictions of Empowerment," International Journal of Knowledge, Culture and Change Management, 8, 1: 121-127.

5. Clark, D. (2007). "Why Silicon Valley is Rethinking the Cubicle Office," Wall Street Journal: October 15.

6. Clarke, B. \& Crossland, R. (2002). The Leader's Voice. New York: SelectBooks.

7. Giacalone, R. A. \& Jurkiewicz, C. L. (2001). "Lights, Camera, Action: Teaching Ethical Decision Making through the Cinematic Experience," Teaching Business Ethics, 5, 1: 79-87.

8. Grandey, A. A. (2000). "Emotion Regulation in the Workplace: A New Way to Conceptualize Emotional Labor," Journal of Occupational Health Psychology, 5, 1: 95-110.

9. Grandey, A. A. (2003). "When the Show Must Go On: Surface Acting and Deep Acting as Determinants of Emotional Exhaustion and Peer-Rated Service Delivery," Academy of Management Journal, 46, 1: 86-96.

10. Kanter, R. M. (1980). "Power Failure in Management Circuits," McKinsey Quarterly, 3: 68-87. 
11. Kanungo, R. N. (1992). "Alienation and Empowerment: Some Ethical Imperatives in Business," Journal of Business Ethics, 11, 5/6: 413-422.

12. Lauder, R. (2002). "Business, Cinema, Sin," Teaching Business Ethics, 6: 63-72.

13. Lewicki, R. J. \& Bunker, B. B. (1996). "Developing and Maintaining Trust in Work Relationships," in R. M. Kramer \& T. R. Tyler (Eds.), Trust in Organizations: Frontiers of Theory and Research. London: Sage Publications, 114-139.

14. Logan, M.S. \& Ganster, D. (2007). "The Effects of Empowerment on Attitudes and Performance: The Role of Social Support and Empowerment Beliefs," Journal of Management Studies, 44: 1523-1531.

15. Maslin, J. (1983). "Peter Hyams Directs Star Chamber," New York Times: August 5.

16. Michaelson, C., Gerde, V., Goldsby, M. G., Orlitzky, M., \& Schoepner, C. (2006). "Bringing the Power of Film to Business Ethics Research and Teaching," Academy of Management Annual Meeting Panel Symposium: 1-14.

17. Nahavandi, A. (2009). The Art and Science of Leadership. Upper Saddle River, NJ: Pearson Prentice Hall.

18. Proctor, R. F. \& Adler, R. B. (1991). "Teaching Interpersonal Communication with Feature Films," Communication Education, 40: 393-400.

19. Sandel, M. J. (2009). Justice: What's The Right Thing To Do?. New York: Farrar, Straus \& Giroux.

20. Serey, T.T. (1992). "Carpe Diem: Lessons about Life and Management from Dead Poets Society," Journal of Management Education, 16, 3: 374-381.

21. Spreitzer, G. M. \& Doneson, D. (2008). „Musings on the Past and Future of Employee Empowerment, „, in T. G. Cummings (Ed.), Handbook of Organizational Development. Thousand Oaks, Ca: Sage Publications, 311-324.

22. Van Es, R. (2003). “Inside and Outside 'The Insider': A Film Workshop in Practical Ethics,” Journal of Business Ethics, 48, 1: 89-97.

23. Zimmerman, M. A. (1990). "Taking Aim on Empowerment Research: On the Distinction Between Individual and Psychological Conceptions," American Journal of Community Psychology, 18, 1: 169-177. 


\section{NOTES}

